\title{
Morbidity and Mortality Related to Obstetrical Evacuations in a Country with Limited Resources: The Case of the Maternity Ward of the Prefectural Hospital of Coyah, Guinea
}

\author{
Mamadou Hady Diallo1*, Ibrahima Sory Baldé2 , Fatoumata Bamba Diallo', \\ Alpha Boubacar Barry ${ }^{2}$, Massa Keita ${ }^{2}$, Emile Tinguiano ${ }^{3}$, Telly Sy², Namory Keita1 \\ ${ }^{1}$ University Department of Gynecology-Obstetrics, Donka National Hospital, Conakry, Guinea \\ ${ }^{2}$ University Department of Gynecology-Obstetrics, Ignace Deen National Hospital, Conakry, Guinea \\ ${ }^{3}$ Maternity Ward of the Prefectural Hospital of Coyah, Coyah, Guinea \\ Email: *hadydiallo2002@yahoo.fr
}

How to cite this paper: Diallo, M.H., Baldé, I.S., Diallo, F.B., Barry, A.B., Keita, M., Tinguiano, E., Sy, T. and Keita, N. (2021) Morbidity and Mortality Related to Obstetrical Evacuations in a Country with Limited Resources: The Case of the Maternity Ward of the Prefectural Hospital of Coyah, Guinea. Open Journal of Obstetrics and Gynecology, 11, 1140-1150. https://doi.org/10.4236/ojog.2021.119108

Received: July 31, 2021

Accepted: September 11, 2021

Published: September 14, 2021

Copyright $\odot 2021$ by author(s) and Scientific Research Publishing Inc. This work is licensed under the Creative Commons Attribution International License (CC BY 4.0).

http://creativecommons.org/licenses/by/4.0/

\section{(c) (i) Open Access}

\begin{abstract}
Obstetric complications requiring evacuation are found all over the world with a high frequency in developing countries where they are responsible for high fetal-maternal morbidity and mortality. The objectives of this study were to calculate the frequency of obstetric evacuations in the maternity ward of the Coyah prefectural hospital, describe the socio-demographic characteristics of the evacuated patients, identify the main reasons for evacuation, determine the means of transport used and specify the maternal and fetal prognosis. Patients and Method: This was a prospective descriptive and analytical study conducted over a 6-month period (April 1-September 30, 2020) at the maternity ward of the Coyah prefectural hospital. All patients evacuated for complications of gravidopuerperium were included in the study. Results: We recorded 84 cases of obstetric evacuations out of a total of 2206 consultations, i.e. a frequency of $3.8 \%$. The average age of the patients was 25.22 years with extremes of 15 and 45 . Housewives (58.82\%), nulliparous women $(36.93 \%)$ and women with no education (64.29\%) were the most numerous ones. No patient received medical transportation. More than half of the patients were evacuated by a nurse (51.21\%). Hemorrhage in the last quarter was the main reason for evacuation. The average distance traveled by patients was $18.3 \mathrm{~km}$ with extremes of 12 and $68 \mathrm{~km}$. The average transfer time was 63 min (1 h 3 minutes) with extremes of $20 \mathrm{~min}$ and $300 \mathrm{~min}(5 \mathrm{~h})$. Maternal mortality was $5.95 \%$. The perinatal mortality rate was $46.42 \%$. No counter-referral was made. Conclusion: The obstetrical prognosis of evacuated
\end{abstract}


women is still poor. We recommend the establishment of an obstetrical SAMU (UAS) system in rural areas in order to contribute to the regulation of obstetrical evacuations, but especially to enable low-income patients to have access to the service.

\section{Keywords}

Morbidity, Mortality, Obstetrical Evacuations, Maternity, Guinea

\section{Introduction}

The maternal mortality ratio is still high in Guinea (550 deaths per 100,000 live births) [1], much higher than in developed countries where it varies from 5 to 30 maternal deaths per 100,000 live births [2], despite the significant progress made under the national program to reduce maternal mortality. The management of obstetric evacuations and their complications has become a public health problem in developing countries. The difficulties are characterized by a limited technical platform, dysfunctional services, the scarcity of blood products and the shortage of qualified health personnel. All pregnant women are at risk of obstetrical complications, which can be fatal and unpredictable, and which are not always identified during antenatal consultations (ANC). Obstetric complications are encountered throughout the world, with a high frequency in developing countries where they are responsible for a high fetomaternal morbidity [3] [4]. When they are present, these complications are often the cause of obstetrical evacuations which take into account a hierarchy in the health system because they occur from a lower level (a health center) to a higher level (a hospital).

Obstetrical referrals are associated with $70 \%-90 \%$ of maternal deaths recorded in hospitals according to Perrin et al. [5]. Although these referrals aim to reduce maternal-fetal morbidity and mortality, specific complications of referred patients are poorly documented in our environment.

The objectives of this study were to calculate the frequency of obstetrical evacuations at the maternity ward of Coyah prefectural hospital, to describe the socio-demographic characteristics of evacuated patients, to identify the main reasons for evacuation, to determine the means of transportation used, and to specify the maternal and fetal prognosis.

\section{Patients and Method}

The maternity ward of the Coyah prefectural hospital served as the study setting. It is a level II maternity hospital located $50 \mathrm{~km}$ away from the capital city, Conakry, on the National Road $\mathrm{N}^{\circ} 1$, and it is intended to admit pregnant women or those evacuated from health centers and private clinics in the Coyah health district. It was a cross-sectional study of descriptive and analytical type with prospective data collection for a period of 6 months from April 1 to September 30, 
2020. The study population consisted of all women evacuated from lower level structures for obstetrical problems and treated at the maternity ward of Coyah prefectural hospital. We conducted an exhaustive census of all cases of obstetrical evacuation. Data were collected upon arrival of patients using a pre-established survey sheet.

Regarding the inclusion criteria, all patients admitted for complications of gravidopuerperium were included.

Non-obstetrical emergencies and maternal deaths on admission (body dumping) were not included. Variables studied were socio-demographic and clinical characteristics, evacuation data, hospital management and maternal and fetal prognosis. Data were collected manually and then analyzed by the software epi info version 3.5.1.

From an ethical point of view, administrative authorizations were obtained to conduct the study and confidentiality was observed.

Limitations and difficulties: The data can only be applied to the study site. The unavailability of certain additional tests and the lack of a blood bank made it difficult to provide adequate management.

\section{Results}

1) Overall frequency of obstetrical emergencies: We recorded 84 cases of obstetrical evacuations out of a total of 2206 consultations, i.e. a frequency of $3.8 \%$.

2) Socio-demographic characteristics: The average age of our patients was 25.22 with extremes of 15 and 45 . The socio-demographic profile of the women concerned was in most cases that of a young, housewife, nulliparous, mostly married woman (Table 1).

\subsection{Distance Traveled}

Less than $15 \mathrm{~km}$ were traveled by $28.57 \%$ of our patients, $32.14 \%$ traveled between 15 and $30 \mathrm{~km}$ and $39.29 \%$ traveled more than $30 \mathrm{~km}$. The average distance traveled by patients was $18.3 \mathrm{~km}$ with extremes of 12 and $68 \mathrm{~km}$.

\subsection{Means of Transportation Used}

No patient received a medical transportation. Public transportation was used in $100 \%$ of cases, i.e., car taxis in $47.61 \%$ of cases and motorcycle taxis (two-wheeled vehicles) in more than half of the cases (52.39\%).

\subsection{Qualification of the Evacuating Agent}

More than half of the patients were evacuated by a nurse (51.21\%), 23.8\% by a matron, $19.04 \%$ by a midwife, and only $5.95 \%$ by a medical doctor.

\subsection{Antenatal Consultation}

No ANC was performed in $28.57 \%$ of our patients; $39.29 \%$ had less than 3 ANCs and $32.14 \%$ had more than 3 ANCs. More than half of the patients had less than 
Table 1. Socio-demographic characteristics.

\begin{tabular}{|c|c|c|}
\hline Sociodemographic Characteristics & Number & Pourcentage \\
\hline \multicolumn{3}{|l|}{ Age (years) } \\
\hline $15-19$ & 23 & 27.38 \\
\hline $20-24$ & 18 & 21.42 \\
\hline $25-29$ & 17 & 20.23 \\
\hline $30-34$ & 17 & 20.23 \\
\hline $35-39$ & 6 & 7.14 \\
\hline $40-44$ & 2 & 2.41 \\
\hline 45 & 1 & 1.19 \\
\hline Total & 84 & 100 \\
\hline \multicolumn{3}{|l|}{ Occupation } \\
\hline Housewives & 49 & 58.82 \\
\hline Liberal occupations & 20 & 23.33 \\
\hline Secondary school and university students & 14 & 16.66 \\
\hline Wage earners & 1 & 1.19 \\
\hline Total & 84 & 100 \\
\hline \multicolumn{3}{|l|}{ Parity } \\
\hline Nulliparous & 31 & 36.93 \\
\hline Primipara & 19 & 22.61 \\
\hline Pauciparous & 4 & 4.76 \\
\hline Multiparous & 20 & 23.80 \\
\hline Large multiparous & 10 & 11.90 \\
\hline Total & 84 & 100 \\
\hline \multicolumn{3}{|l|}{ Marital Status } \\
\hline Married & 68 & 80.96 \\
\hline Divorced & 8 & 9.52 \\
\hline Singles & 5 & 5.95 \\
\hline Widows & 3 & 3.57 \\
\hline Total & 84 & 100 \\
\hline \multicolumn{3}{|l|}{ Educational Level } \\
\hline Not enrolled in school & 54 & 64.29 \\
\hline Primary educational level & 21 & 25 \\
\hline Secondary educational level & 7 & 8.33 \\
\hline Higher educational level & 2 & 2.38 \\
\hline Total & 84 & 100 \\
\hline
\end{tabular}

3 ANCs. The average number of ANCs was 1.2 with extremes of 0 and 5 .

The discrepancy between the reason for evacuation and the admission diagnosis was more marked for acute fetal sufferings (Table 2).

Management before evacuation: only 4 patients out of 84 had a venous approach before evacuation $(4.76 \%)$. The solution used was isotonic saline in 1 
Table 2. Distribution of evacuees by reason for evacuation and admission diagnosis.

\begin{tabular}{lcc}
\hline \multicolumn{1}{c}{ Morbidity } & $\begin{array}{c}\text { Reasons for evacuation } \\
\mathbf{n}(\%)\end{array}$ & $\begin{array}{c}\text { Admission diagnosis } \\
\mathbf{n}(\%)\end{array}$ \\
\hline Dynamic dystocia & $21(25)$ & $13(15.47)$ \\
Mechanical dystocia & $9(10.71)$ & $17(20.23)$ \\
Uterine rupture & $17(20.23)$ & $21(25)$ \\
Eclampsia & $10(11.9)$ & $10(11.9)$ \\
Pre-eclampsia & $6(7.14)$ & $6(7.14)$ \\
Retro placental hematoma & $7(8.33)$ & $9(10.71)$ \\
Vicious presentation & $8(9.52)$ & $7(8.33)$ \\
Uterine atony & $0(0)$ & $4(4.76)$ \\
Placental Retention & $1(1.19)$ & $3(3.57)$ \\
Placenta previa & $5(5.95)$ & $4(4.76)$ \\
Acute fetal suffering & $7(8.33)$ & $49(58.33)$ \\
\hline
\end{tabular}

case (1.19\%) and lactated ringer in 3 cases (3.57\%). It was noted that no patient received macromolecules or transfusion before evacuation.

\subsection{Travel Time}

The average travel time from the time of the transfer decision to the arrival at the transfer location was 63 minutes ( 1 hour 3 minutes) with a maximum of 300 minutes ( 5 hours) and a minimum of 20 minutes.

Hospital care on arrival: this was marked by the third delay linked to the lack of operating kits, the unavailability of the unit, the lack of blood products. The average time taken to take charge was 31 minutes with extremes of 15 and 165 minutes ( $2 \mathrm{~h} 45 \mathrm{~min}$ ).

All patients who died had traveled more than $30 \mathrm{~km}$ with a statistically significant difference (Table 3).

The means of evacuation, the level of education, the number of antenatal visits and the parity did not significantly influence the maternal prognosis.

The newborns to women transported by motorcycle taxis, having received less than 3 ANCs, nulliparous women having travelled a distance of more than 30 $\mathrm{km}$ were the most affected with a statistically significant linkage (Table 4).

\subsection{Maternal and Perinatal Mortality}

During the study, 5 maternal deaths were recorded, i.e., a percentage of maternal deaths among evacuated women of $5.95 \%$, and 39 perinatal deaths, i.e., a perinatal lethality rate of $46.42 \%$.

\subsection{Means of Counter Reference}

No counter reference was made. 
Table 3. Characteristics related to maternal prognosis.

\begin{tabular}{|c|c|c|c|c|}
\hline & $\begin{array}{c}\text { Dead } \\
\text { Women }\end{array}$ & $\begin{array}{c}\text { Women Alive } \\
\text { n (\%) }\end{array}$ & $\begin{array}{l}\text { Total } \\
\text { n (\%) }\end{array}$ & $\mathrm{Chi}^{2} \mathrm{P}$ \\
\hline Means of evacuation & & & & $\begin{array}{c}\mathrm{Chi}^{2}=0.393 \\
\mathrm{P}=0.53\end{array}$ \\
\hline Car Taxis & $3(3.57)$ & $36(42.85)$ & $39(46.42)$ & \\
\hline Motorbike Taxis & $2(2.38)$ & $43(51.19)$ & $45(53.57)$ & \\
\hline Educational Level & & & & $\begin{array}{c}\mathrm{Chi}^{2}=0.827 \\
\mathrm{P}=0.90\end{array}$ \\
\hline Not enrolled in school & $4(4.76)$ & $50(59.52)$ & $54(64.28)$ & \\
\hline Primary educational level & $1(1.19)$ & $20(23.80)$ & $21(25)$ & \\
\hline Secondary educational level & $0(0)$ & $7(8.33)$ & $7(8.33)$ & \\
\hline Higher educational level & $0(0)$ & $2(2.38)$ & & \\
\hline Number of ANCs & & & & $\begin{array}{c}\mathrm{Chi}^{2}=2.518 \\
\mathrm{P}=0.11\end{array}$ \\
\hline$<3$ & $5(5.95)$ & $52(61.9)$ & $57(67.85)$ & \\
\hline$\geq 3$ & 0 & $27(32.14)$ & $27(32.14)$ & \\
\hline Parity & & & & $\begin{array}{c}\mathrm{Chi}^{2}=7.015 \\
\mathrm{P}=0.10\end{array}$ \\
\hline 0 & $3(3.57)$ & $28(33.33)$ & $31(36.9)$ & \\
\hline 1 & $0(0)$ & $19(22.61)$ & $19(22.61)$ & \\
\hline $2-3$ & $0(0)$ & $4(4.76 \%)$ & $4(4.76 \%)$ & \\
\hline $4-6$ & $0(0)$ & $20(23.80)$ & $20(23.80$ & \\
\hline$\geq 7$ & $2(2.38)$ & $8(9.52)$ & $10(11.9)$ & \\
\hline Traveled Distance & & & & $\begin{array}{c}\mathrm{Chi}^{2}=8.21 \\
P=0.004\end{array}$ \\
\hline$<30 \mathrm{~km}$ & $0(0)$ & $51(60.71)$ & $51(60.71)$ & \\
\hline$\geq 30 \mathrm{~km}$ & $5(5.95)$ & $28(33.33)$ & $33(33.33)$ & \\
\hline
\end{tabular}

\section{Discussion}

\subsection{Frequency}

Women evacuated by peripheral structures during our study period at the Coyah maternity hospital represented $3.8 \%$ of obstetrical consultations. This low rate could be explained by the existence of private clinics equipped to perform cesarean sections in central Coyah and the proximity of the capital city Conakry, which admits serious obstetrical evacuations. Our rate is lower than the data found by various authors. Samaké A et al. reported a frequency of $24.60 \%$ [6]. Sepou A et al. reported a frequency of 27.3\% [7]. Diarra Nama AJ et al. reported a frequency of $7.9 \%$ [3]. This frequency was $31.2 \%$ for Thiam $\mathrm{O}$ et al. [8].

\subsection{Socio-Demographic Characteristics}

The average age of our patients was 25.22 with extremes of 15 and 45 . The average age of the evacuees is comparable to those reported by different authors in 
Table 4. Characteristics related to perinatal prognosis.

\begin{tabular}{|c|c|c|c|c|}
\hline & $\begin{array}{c}\text { Dead babies } \\
\text { n (\%) }\end{array}$ & $\begin{array}{c}\text { Babies alive } \\
\text { n (\%) }\end{array}$ & $\begin{array}{l}\text { Total } \\
\text { n (\%) }\end{array}$ & $\mathrm{Chi}^{2} \mathrm{P}$ \\
\hline Means of Evacuation & & & & $\begin{array}{c}\mathrm{Chi}^{2}=37.23 \\
\mathrm{P}=0.000\end{array}$ \\
\hline Car Taxis & $9(10.71)$ & $40(47.62)$ & $49(58.33)$ & \\
\hline Motorbike Taxis & $30(35.71)$ & $5(5.95)$ & $35(41.67)$ & \\
\hline Number of ANCs & & & & $\begin{array}{c}\mathrm{Chi}^{2}=32.01 \\
\mathrm{P}=0.000\end{array}$ \\
\hline$<3$ & $29(34.52)$ & $6(7.14)$ & $35(41.67)$ & \\
\hline$\geq 3$ & $10(11.9)$ & $39(46.42)$ & $49(58.33)$ & \\
\hline Parity & & & & $\begin{array}{c}\mathrm{Chi}^{2}=30.96 \\
\mathrm{P}=0.000\end{array}$ \\
\hline 0 & $22(26.19)$ & $9(10.71 \%)$ & $31(36.9)$ & \\
\hline 1 & $6(7.14)$ & $13(15.47)$ & $19(22.61)$ & \\
\hline $2-3$ & $0(0)$ & $4(4.76)$ & $4(4.76)$ & \\
\hline $4-6$ & $2(2.38)$ & $18(21.42)$ & $20(23.80)$ & \\
\hline$\geq 7$ & $9(10.71)$ & $1(1.19)$ & $10(11.9)$ & \\
\hline Traveled Distance & & & & $\begin{array}{c}\mathrm{Chi}^{2}=39.94 \\
\mathrm{P}=0.000\end{array}$ \\
\hline$<30 \mathrm{~km}$ & $6(7.14)$ & $38(45.23)$ & $44(52.38)$ & \\
\hline$>30 \mathrm{~km}$ & $33(39.28)$ & $7(8.33)$ & $40(47.62)$ & \\
\hline
\end{tabular}

similar studies. Samaké A et al. reported an average age of $26 \pm 5.16$ with extremes of 15 and 44 [6]. Diarra Naman AJ et al. reported an average age of $25.8 \pm$ 7.41 with extremes of 14 and 44 [3]. The high percentage of nulliparous and primiparous women among the evacuees confirms the notion of risk of gravidopuerperium in young women. It is in this group that a high frequency of vasculorenal syndromes and mechanical dystocia is observed. Most of the patients were uneducated and housewives. Sengeyi MAD et al. reported in their series $22 \%$ of uneducated women versus $60 \%$ with secondary education and $8.2 \%$ with university education [9]. Multiparous women represented 57\% of the total referrals against $37 \%$ of primiparous women. A high level of education would help understand the usefulness of ANCs in the prevention of complications.

Distance traveled and means of evacuation: The average distance traveled by patients was $18.3 \mathrm{~km}$ with extremes of 12 and $68 \mathrm{~km}$.

Maternal and perinatal deaths occurred in the majority of cases in patients who were admitted from areas over $30 \mathrm{~km}$ away, with a statistically significant linkage. This could be explained by the geographical inaccessibility of certain remote rural areas and the poor state of the road network, which causes the aggravation of complications. This result corroborates the data of Sépou et al. [10].

The analysis of our results showed that none of the patients in our series received a medical transportation. Evacuations were made using public transporta- 
tion in all cases. This reflects a serious dysfunctioning in the referral/evacuation system at the Coyah health district level, as these patients, most of whom had serious clinical conditions, were transported in taxis or on motorcycles without any comfort or medical assistance. The evacuation in good conditions and under the supervision of a health worker is of great importance.

In the Central African Republic, $26.1 \%$ of evacuations were carried out by ambulance [10]. In rural Senegal, $69.2 \%$ of evacuations were carried out by ambulance [8]. For Samaké A et al. taxis and ambulances were the most used means of transportation with respectively $64.88 \%$ and $24.06 \%$ [6]. These data show that a great deal of effort must be made to equip health posts and centers with ambulances by medical authorities in our country. Thus, to improve the quality of health coverage in rural areas, the creation of operational surgical units and the training and retraining of health personnel appear to be a priority.

Regarding the qualification of evacuating agents, our results showed that evacuations were decided by nurses in more than half of the cases. Sengeyi MAD et al. reported that evacuations were decided by nurses, doctors and midwives with respectively $39.6 \%, 18.2 \%$ and $8.2 \%$ [9]. This could be explained by the fact that in Africa, and particularly in our country, Guinea, the peripheral level of health cares, and specifically health centers, are run by health auxiliaries, particularly nurses, who, when the decision to transfer is necessary, make it.

Most of our patients had no or very little follow-up. This percentage can be explained by the negligence and the lack of real knowledge of the advantages of ANCs by pregnant women.

ANCs make it possible to predict certain risks during pregnancy and also certain complications during delivery.

Serious morbidity and mortality associated with obstetric evacuations highlight the poor quality of prenatal follow-up because a good quality of ANCs decreases the number of patients evacuated and increases the number of referrals (i.e., in the absence of a clinical picture requiring immediate intervention), but the opposite effect occurs. These findings raise the problem of the quality of prenatal follow-up with the objective of detecting high-risk pregnancies and deliveries with a high potential for dystocia, and therefore the issue of early referral of such cases to health facilities providing specialized obstetric care.

The main reasons for evacuation were hemorrhage and dystocia, followed by vasculorenal syndromes and their complications, and the reasons for evacuation were often inconsistent with the admission diagnosis.

Our results are similar to those of Thiam et al. in Senegal who reported dystocia (37.4\%), hemorrhage (31.6\%) and hypertension and its complications (14.2\%) as the main reasons [8].

Our results are similar to those observed in Dakar [11]. This diagnostic discrepancy could be justified by the inadequate qualification of health care providers in health centers who should therefore take refresher courses.

Regarding the mode of delivery, our cesarean section rate at $76.20 \%$ was high. 
Thiam et al. reported a rate of $33.2 \%$ in Senegal [8]. Our rate is significantly lower than that of Soltani in Tunisia (18.5\%) [12]. Our high rate would be related to the severity of obstetrical complications on admission, indicating an absolute need for a Caesarean section.

\subsection{Maternal and Perinatal Prognosis}

The maternal mortality was 5.95\%. All death cases involved women who traveled more than $30 \mathrm{~km}$. These deaths were statistically related to the long distance from the center.

This rate is higher than the data reported by Thiam o et al. (2\%) [8]. The causes were dominated by haemorrhage. These were all difficult to compensate for because adequate resuscitation means were lacking in peripheral areas. This justifies the need to make emergency obstetrical care accessible at health districts levels in rural areas and especially to improve the medicalization of obstetrical evacuations by setting up an emergency medical service in rural areas.

Perinatal mortality was very high in our series (46.42\%). It was mainly attributable to hemorrhage, dystocia and vasculorenal syndromes and their complications. This rate remains higher than that found by Cissé in Dakar (23\%) [11]. Our high rate would be related to late managements. Indeed, with the high proportion of diagnostic errors on the part of the transferring health worker (usually a nurse), the decision to transfer is only made late in the presence of a complication. In addition, there is a lack of adequate transportation means (ambulance). As a result, parturients arrive at the referral facility with serious complications and a fetus that is difficult to recover.

Hospital treatment on arrival was made difficult by the third delay linked to the lack of operating kits, the unavailability of the unit and the lack of blood products.

Regarding the means of counter-referral, no patient benefited from a counter-referral note in our series. Thiam $\mathrm{O}$ et al. reported that counter-referrals were made in $97.3 \%$ of cases. Means used consisted of a mail in $76.8 \%$ and a phone call to the referring provider in $15.6 \%$ [8].

\section{Conclusions}

The reduction of maternal and perinatal morbidity and mortality requires the standardization of evacuation criteria based on risk factors allowing the identification of high-risk pregnancies and deliveries, the training of peripheral health personnel in the recognition of these factors, the instruction of these (pregnant) women on the risks incurred by them and their children, the improvement of the evacuation prognosis and, in the long term, getting referral structures closer. Emergency obstetric and neonatal care must be consolidated in this district where maternal and perinatal mortality remains high. A better organization of the transportation system (ambulance) and the communication between health facilities will contribute to the improvement of the management and the mater- 
nal and fetal prognosis of transferred cases.

We recommend setting up an obstetrical emergency medical reception service in rural areas in order to contribute to the regulation of obstetrical evacuations, but above all to enable low-income patients to have access to the service. The systematization of the counter-referral from the referral health facility to the one that carried out the transfer will also contribute to the improvement of the maternal and fetal prognosis of transferred cases by favoring the sharing of information between the two facilities and by reinforcing the continuity and the quality of care.

\section{Conflicts of Interest}

The authors declare no conflicts of interest.

\section{References}

[1] Direction nationale de la statistique (Guinée) Enquête démographique et de santé à indicateurs multiples (EDS-MICS, 2018) Institut national de la statistique Conakry, Measure, DHS, ICF international Calverton, Maryland, USA 2013:151-178.

[2] Zine, S., Abed, A., Sfar, E., Mouelhi, T. and Chelli, H. (1995) Les ruptures utérines au cours du travail. A propos de 106 cas observés au centre de Maternité de Tunis (Tunisie). Rev Fr Gynecol Obstet, 90, 166, 169-173.

[3] Diarra Nama, A.J., Angbo, O., Koffi, M.N. and Koffi, M.K. (1999) Morbidité et mortalité liées aux transferts obstétricaux dans le district sanitaire de Bouaflé en Côte d'Ivoire. Santé publique, 11, 193-201.

[4] Hohlagschwandtner, M., Husslein, P., Klebermass, K., et al. (2001) Perinatal Mortality and Morbidity: Comparison between Maternal Transport, Neonatal Transport and Inpatient Antenatal Treatment. Archives of Gynecology and Obstetrics, 265, 113-118. https://doi.org/10.1007/s004040100197

[5] Perrin, R.X., Komongui, D.G., et al. (2012) Le système de référence et contre référence dans les maternities: SAMU obstétrical. $U M V F, 10,5$.

[6] Samaké, A., Traore, S.O., Keita, M., Doumbia, S., Diallo, M., Konaté, M., Diarra, L., Maiga, M., Traoré, O.M., Traoré, M.A., Diakité, N., et al. (2020) Les évacuations sanitaires obstétricales dans un Hôpital de deuxième niveau de référence du district de Bamako. Health Sci Dis, 21, 96-99.

[7] Sepou, A., Yanza, M.C., Nguembi, E., Dotte, G.R. and Nali, M.N. (2000) Analyse des évacuations sanitaires en gynécologie obstétrique à Bangui, Centrafrique; cahiers d'études et de recherches francophones/Santé. Journal, 10, 399-405.

[8] Thiam, O., Cissé, M.L., Mbaye, M., Niang, M.M., Gueye, M., Diouf, A., Dieye, S. and Moreau, J.C. (2013) La problématique des parturientes évacuées en zône rurale sénégalaise: Exemple du centre hospitalier de Ndioum. Rev. Cames Santé, 1, 51-56.

[9] Sengeyi, M.A., Kahindo, M.P., Kamata, Kayembe, M.C. and Nembunzu, D. (2016) Références dans le service d'Obstétrique de l'Hôpital Saint Joseph de Kinshasa en 2013. Revue médicale des Grands Lacs, 7, 9-13.

[10] Sepou, A., Yanga, M.C., Nguembi, E., et al. (2003) Aspects épidémiologiques et cliniques de 116 cas de GEU à l'Hôpital Communautaire de Bangui. Med Afr Noire, 50, 405-411.

[11] Cissé, M.L., Moreau, J.C., Faye, E.H.O., Cissé, L., Terolbe, I. and Diadhiou, F. (2002) 
Coût de l'évacuation des parturientes au centre hospitalo universitaire Aristide Le Dantec de Dakar. JSAGO, 1, 23-27.

[12] Soltani, M.S., Bechir, A. and Souissim, M.B. (1991) Profil des grossesses référées au Sahel tunisien. Rev. Fr. Gynécol. Obstét, 86, 511-513. 